Copyright ( $) 2016$ SCAD Independent

All Rights Reserved

Printed in the Indonesia
Jurnal Ilmiah Peuradeun Vol. 4, No. 3, Sep 2016

\title{
INFORMAL EDUCATION AS A PROJECTED IMPROVEMENT OF THE PROFESSIONAL SKILLS OF EMPLOYEES OF ORGANIZATIONS
}

\author{
Warul Walidin \\ Ar-Raniry State Islamic University, Banda Aceh, Indonesia \\ Email:warul.walidin@gmail.com
}

Received: Dec 15, 2015

Accepted: May 28, 2016

Published: Sep 28, 2016

Article Url: https://journal.scadindependent.org/index.php/jipeuradeun/article/view/103

\begin{abstract}
Technologies of vocational training play an important role in the concept of informal education and they can be implemented as in higher education, and organizational learning. In the modern understanding of education the two sides are emphasized the communion of each person to the society and the development of individual personality features. If formal education is moving towards these goals systematically and purposefully at certain training sessions, the place and time of informal education is in no way limited. Informal education can be characterized not only by independent, human progress in cultural development, but also directed and projected improvement of professional and personal skills of employees of organizations. The purpose of this papers to examine informal education not only as an independent, but also as a guide and the projected improvement of the professional and personal skills of employees of organizations. The leading approaches to the study of this problem are social-pedagogical and managerial approaches to substantiate the essence of the process and the role of leaders of organizations trained in the management of such education.
\end{abstract}

Keywords: Informal Education, Personal Skill, Employees Organizations, Cultur 


\section{A. Introduction}

Theorists of management (Nonaka, Toyama \& Hirata, 2008) concluded that innovation in organizations often rely on intuitive feelings and vague guesses of employees "to create the new knowledge it is necessary to be able to test and use subjective views, insights and inspiration of employees across the company", which entails the activation of informal education organizations, "individual cognitive activity that accompanies everyday life and is not necessarily focused". The modern world is called "knowledge society"; one of the features of it is that the creation of new knowledge is not limited to the mechanical processing of objective information. Life in the face of constant changes and uncertain values requires "conscious design, so that educational opportunities need to be developed consciously". This idea of I. Illich (2006) is reflected in management.

Informal education, like any social phenomenon, has certain connections and relations. Informal education is a self-organizing process, but its reflection and recovery can be put into practice by leaders who understand the nature and role of education in the efficiency of the organization. The vision of education (social and pedagogical) management functions of the leaders is formed in the course of their training.

Therefore, technologies of vocational training play an important role in the concept of informal education and they can be implemented as in higher education, and organizational learning. We analyze them guided by the theory of social pedagogy (informal education is not at odds with the fact that the German philosopher P. Natorp (1899) at the beginning of the last century called "natural scientists") and the theory of modern management, that learnt to work as with a "clear" and with the "implisit" knowledge (which is also equivalent to informal education).

\section{B. Method}

The basis of the study was experimental work using diagnostic techniques of Kelly grid (Kelly, 1955) to monitor changes in vision heads of educational opportunities organizations and the development of their socialpedagogical competence. Experimental work was comprehensive and 
covered the development of competencies managers and actually management processes in informal education organizations. During the study following the methods were used: the subject of analysis and research problems based on the study of philosophical, psychological, sociological, cultural, educational literature, analysis and synthesis of empirical data, modeling, comparative historical and logical analysis, the methods of structural and system analysis, retrospective analysis of their own socialpedagogical and administrative activity) and empirical study, was the study and generalization of mass and progressive social-pedagogical and management experience, documentation, results of group discussion, creative work product managers, interviews, and observation.

\section{Theoretical Framework \\ 1. Social-Pedagogical and Managerial Approach}

In the modern understanding of education the two sides are emphasized - the communion of each person to the society and the development of individual personality features. In addition, education is defined as "the restructuring or reorganization of experience" as a basis for understanding one self and others (Dewey, 1916). If formal education is moving towards these goals systematically and purposefully at certain training sessions, the place and time of informal education is in no way limited: self-education, and direct networking, travel and so on.

Various methodological orientations can be selected for the study and understanding of informal education: self-education, adult education, e-learning, free education, open education and other areas of pedagogy, an alternative with respect to the normalized reality of school. We seem views on education in the community (social pedagogy) P. Natorp (1899), to be most productive for the development of informal education based on the work that we have identified patterns of informal education and the principles of social-educational activities. We consider informal education, not distinguishing between training and education. Actually, this approach has historically occurred and is reproduced, for example, by V.V. Davydov (1991): "It was during this period in the system of developmental education or practice, nor theorists were not inclined to 
specifically break down, much less to oppose education and training these were moments of a unified and holistic educational process" (Davydov, 1991). Patterns of informal education:

a. Significant impact on informal education of the close community, where everyone from the close circle have their own interests and hobbies, which can turn around the communication;

b. The pursuit of development inherent in every human being is able to prevail over consumer demands in the case where the independence is not violated in the selection and decision-making.

The principles of social-pedagogical activities:

a. The principle of isomorphic of educational objectives to the trends of social development;

b. The principle of "natural conditions": informal education is included in the ordinary conditions of life;

c. The principle of enriching the culture of the professional community.

Informal education in the organization can be as spontaneous as well as guided and projected. It must be admitted that "management informal Education" - a paradoxical expression, in fact, an oxymoron. Ideally, the training activities are generated at school. However, as it was noted even by Dewey (1916), cognitive motivation of many people over time, is lost or becomes dull due to various reasons. Therefore, managers need to make efforts to enhance educational processes: to organize cooperation on the problem-solving, encourage creativity, and - as a special case - to norm-setting, to set the personality of significant and sometimes unexpected problems, to maintain the interests of the individual. In order to determine the necessity and sufficiency of such actions, it is important to introduce them to the functional managers, defining the content and place among other administrative functions.

\section{Social-Pedagogical Management}

Projected informal education is a result of the development, which requires a separate description. One of the tasks of management is to 
contribute to the satisfaction of personal needs and interests of people. Leaders care about the employee primarily by satisfying his needs related to the core business - namely, the need for work and comfortable working conditions, in obtaining material reward and public recognition for his work, the need for the warmth of human relations and respect for his identity, in the realization of his abilities and opportunities. But there is also a higher demand - in the development, self-actualization, and the ones that can be carried to the culture rather than to the psychological and social aspects. We refer here to T. Parsons (1949), who believes that "specific action system - i.e. personality and social systems - have psychological, social and cultural aspects. Systems of culture have their own forms and integration problems that are not reducible to any person or to the social system, or to both together".

Actualization of the relationship "social-pedagogical activity leaders informal Education" allows you to organize the working life on the technology embodied in the modern management principles of social pedagogy. Channeled informal education is a direct result of educational interaction of the manager and the employee, social-educational support activities such as: coaching, support, mentoring, and tutorship. Social-pedagogical management should be allocated from other social functions; they have their own specifics, motivation and regulatory framework. Social-pedagogical management - a purposeful influence on the development of the individual in the organization and its external environment.

\section{Communication and informal Education}

Existential and communication technologies are a gradual creation of a vision and informal education - as a result - subjective understanding of important features of the profession. Communication in the creative process and chat about art is the key to self-knowledge.

1st stage of existentially and communication technologies: the figurative design of the problem. It is important to offer each employee participating in a collective discussion of an issue, focusing on their emotions, which are caused by the stated problem for discussion. This is facilitated by a 
specially -designed questionnaire, motivators or selected for the proposed situation artistic samples from various types of art. As a non-verbal language, allowing a person to activate the self-study process, are well suited expressive arts (painting, sculpture, collage, involuntary letter). According to the technique chosen in the first phase, the type of existential and communication technologies is determined : the attempts of their own creative staff starts as art communication; free discussion of recognized masterpieces of art leads to the "aesthetic communication"; thinking, given by the questionnaire-motivator - part of reflexive communication.

2nd stage of existentially and communication technologies: understanding of the proposed images. Each participant free creativity (this is, in fact, is the activities of the non-verbal methods), reflective (questionnaire-motivator) or free thinking (on the themes of the book, a movie or picture) pronounces what happened in the course of the assignment, interprets images, finds their verbal incarnation - personal constructs, indicating an interest in solving the problem, which can occur under different slogans. It is important that members of the team solving the problem, used comprehensible systems and models (personality constructs as defined by G.A. Kelly (1955), and the discussion of a variety of constructs as a basis of understanding of their own and others' social value orientations.

3rd stage of existentially and communication technologies: a search partnership. The basis of this phase - the interaction in the group. The head of the group, depending on the keywords voiced during the discussion structures further questions and finds out the necessary organizational forms that allow people to be included in the discussion, to appreciate someone else's opinion, to defend his point of view or, conversely, to come to a different point of view. Members of the discussion find adequate designation of the processes that they are investigating. The understanding and implementation of the first phase of the task is different. Opinions collide, contradict each other. There are doubts, for the resolution of which an act of choice by opting for one (not necessarily it's originally) verbalized construct is required. It is likely that no one will emerge the preferred model and formed the range of possible approaches. 
The proposed logic - the general for the existential and communication technologies - allows you to make professional staff perceptions of problems and solutions more personal and more "emotional". Let us dwell briefly on the features of each type of existential communication technologies.

Art communication. The creative potential of every individual in solving professional problems and finding representations of themselves in the profession is actively involved. Small groups will present the main idea of the original solution of the problems in a creative form, where any piece of everyday life can be raised to the level of art. In collaboration with a team of professionals, we appeal to those kinds of contemporary art, which themselves are of interest: installations, happenings and performances. Working in this mode is not just a collective creation. Our observations highlight - as an aftereffect - a fundamentally important level of understanding. The following discussion deepens the understanding of the staff's attitude to the issue, which was the center of attention.

Aesthetic Communication. The basis for the discussion can become an individual meeting of every person with recognized masterpieces of art - a book, a painting or a feature film. Since in this case we are talking about the possibilities of existentialism, we attract people's attention to the works, allowing to enter the discussion of moral conflicts and philosophically significant concepts.

Reflective communication. A new accents "actually perceived world as our senses" (Schutz, 1968) make proper emphases. We offer participants in problem groups, questionnaires motivators to help to their own perceptions of life events, the analysis of which is important for understanding the processes of support of the individual, the value of the organization, and other aspects of life of the professional community.

The most controversial issue relating to the development of informal education in various organizations is the question of responsibility for education. One can doubt who is in charge of educational processes: top managers, line managers, service personnel development, coaches, and organizational psychologists. Education management in the organization, a 
direct duty of the leaders, and in this case is necessary to prepare managers for the role of the educational mentor.

Educational activity is not leading to different types of organizations; therefore, the adoption of it by the leaders is associated with certain difficulties to overcome in the course of their professional education through the existential communication technologies. As educational technology existentially -communication technologies are the tools to build a vision of educational opportunities for any organization by students as future leaders.

\section{Discussion}

Effective personnel policy, according to organizational psychologists, includes not only the selection of personnel and their safety, but also the promotion of social competence of specialists: openness to new, ingenuity, endurance - a stable background of professional success. Experts in the field of control in management and management psychology have long noted that the organization of the structure, culture and objectives of the system have an impact on employees. This makes it possible to search for an organizational culture in which every person can use his work for self-improvement his strengths. Therefore, the organization can provide employees with the opportunity to play sports, to establish a balance between work and free time, offer employees assistance in times of crisis and to support them in their quest to make a harmonious personality (Kirchler, 1995).

The term "educational support" has become widely used, thanks to the work O.S. Gazman (1995), indicating a joint process with the young individual to determine his own interests, goals, possibilities and ways of overcoming obstacles; to keep his dignity and self achieve the desired results in education, self-education, communication, lifestyle. In general, a support of a person may be defined as assistance to a person in the implementation of his current (for this age and in this situation) development needs. Adults tend to self-realization and self-efficacy. For the "mature" person, according to psychology, characteristic of activity, 
independence, faith in their abilities, the presence of permanent objectives, a high level of subjective control over their behavior are characteristic features. To support an employee means to relate his personal needs with organizational goals and allow him to choose the means of achieving these goals.

The objectives and in accordance with them the support of a person are different at different stages of human involvement in the activities of the company. M. Hilb (2005) describes four phases of workers progress. The introductory phase consists of hiring workers with potential for development, and the rapid familiarization with their new tasks and working conditions. This phase should take as little time as possible. In the growth phase, on the contrary, the workers must be as long as possible. This can be done by offering them the task to ensure the purpose and interest and provide free activity. Maturity phase includes employees who demonstrate high performance but low growth potential; finally, these workers can move in the saturation phase when performance begins to decrease also. To avoid this, employees can be offered two options: take a new position in which they will be able to reconsider its position and thus return to the introductory phase, or to help a person find a suitable job outside the organization.

Developing the idea of support, we believe that the manager can assist employees in their relationships - to the world, to people, to themselves, to the profession, with the help of the following methods:

a. The participation of the head in the professional fate of the employee (definition of super personal purposes - work not only on income, help in choosing which position gives greater opportunity to realize themselves in the profession);

b. Attracting experienced staff to mentoring;

c. If not encourage, show the loyalty to the interests of employees;

d. Activation of the adaptive functions of the labor community (development of people interaction skills, abilities make emotional overload, social creativity), etc. 
Support can be considered as a special psychotechnical method, which is the basis of constructive interaction with people. Support in this case is to promote a person in a situation where he feels challenged in the action, made in the form of direct speech utterance (Krivtsova \& Muhamatulina, 1997). To provide communication support manager must see that an employee has a problem, find a comfortable situation, and join in the conversation. It is important to not only express their opinions, but also to show the man, he is listened closely, the manager understands his problem, and he is recognized as a person. This type of influence on the person compensates for the lack of traditions in modern society, where everyone is forced to turn to their own resources to build his own biography. This support facilitates the selection, enables the person to cope with his difficulties. Support can be real (friendly participation, transfer to another position, help with the work), communication and indirect (through the activities of specially-organized training group or through the influence of a real team, if the working group is due to the degree of development).

In support logic manifests itself the management of "coaching" style. It is characterized by vision in employee's people with their values, aspirations, and personal goals. Man needs nourishment, encouragement and light, but the ability to grow into a powerful establishment is already incorporated in him. Support and coaching can be seen as a socialpedagogical activity of leaders, leading to the guide informal education.

Back in the 1970's American-made human resource management programs to improve the quality of working life, which J.R. Hackman \& J.L. Suttl (1977) defined as the degree to which members of the production organization can meet their important personal needs through their work in the organization. In addition to the approach "from problems" and "the problems of search" there is a possible way to stimulate and reinforce the spiritual well -being of the individual - to develop specific organization of life of people in the real world.

The real breakthrough in the creation of a developing working environment was the theory of learning organization. The student can be 
considered as an organization which is able to create, acquire and disseminate knowledge and change their behavior as the result of new information, in accordance with the original ideas and modern models of thinking. C. Argyris (2004) first noted that it is possible not only to react to external changes, but to anticipate them and manage them in advance, if we consider the training of individual employees as an organizational learning, consolidating individual research results and in the minds of staff and in terms of organization. One of the followers of the concept P. Senge (1990), focuses on the five skills of the organization:

a. To refine and deepen the personal and professional potential of each employee.

b. To relate management ideas with stereotypes regarding various industrial and domestic situations.

c. To build a common vision for the future of the organization.

d. To educate the team: it's not just about training courses or seminars, but also on the free exchange of ideas in groups.

e. To develop systems thinking, that allows you to see not individual events, but deep relationship.

Learning organization suggests that Education - not just the accumulation of knowledge and the development of meaningful use of their skills. Technology learning organization as much as possible contributes to informal education. In a learning organization the manager is responsible for the creation of structures, where employees are constantly expanding opportunities to influence their future. $\mathrm{He}$ is at the same time a designer, a teacher and manager who creates the conditions for developing a common vision and casts doubts on the accepted modes of thinking.

\section{E. Conclusion.}

Technologies of vocational training play an important role in the concept of informal education and they can be implemented as in higher education, and organizational learning. In the modern understanding of education the two sides are emphasized - the communion of each person to the society and the development of individual personality features. In 
addition, education is defined as "the restructuring or reorganization of experience" as a basis for understanding one self and others. If formal education is moving towards these goals systematically and purposefully at certain training sessions, the place and time of informal education is in no way limited: self-education, and direct networking, travel and so on.

Informal education can be characterized not only by independent, non -programmed human progress in cultural development, but also directed and projected improvement of professional and personal skills of employees of organizations. However, the main focus in the development of informal education leaders must do its spontaneity, providing more opportunities for developing independence and initiative of each employee.

Educational activity is not leading to different types of organizations; therefore, the adoption of it by the leaders is associated with certain difficulties to overcome in the course of their professional education through the existential communication technologies. As educational technology existentially -communication technologies are the tools to build a vision of educational opportunities for any organization by students as future leaders. To activate informal education systematically, leaders of organizations need to prepare for this type of management. This research shows that managers' training is in the sphere of personal responsibility and it helps professional education, one of the elements of which are existential and communication technologies. These technologies catalyze the informal education directly to the company, firm or in manufacturing.

\section{Bibliography}

Argyris, C. (2004). Reasons and Rationalizations: The Limits of Organizational Knowledge. Oxford, New York: Oxford University Press.

Buseri, K. (2015). Epistemologi Islam dan Reformasi Wawasan Pendidikan. Jurnal Ilmiah Peuradeun, 3(1), 77-102.

Chapaev, N. K. \& Efanov, A. V. (2013). On the question of the development of the "theory of practice". The education and science journal, 2, 51-60. 
Davydov, V. V. (1991). L.S. Vygotsky and the problems of educational psychology. Moscow: Pedagogy.

Deming, W. E. (1982). Out of the crisis: quality, productivity and competitive position. Cambridge: Cambridge University Press.

Dewey, J. (1916). Democracy and education. New York: The Macmillan Company.

Drucker, P. F. (2003). A functioning society: selections from sixty-five years of writing on community, society, and polity/ Peter F. Drucker; chosen and edited by the author. Brunswick, London: Transaction Publishers.

Fromm, E. (1976). To Have or To Be? London, New York: Continuum.

Gazman, O. S. (1995). The new value of education: the contents of humanistic education. Moscow: Without publishing.

Hackman, J. R. \& Suttle, J. L. (1977). Improving life of work. Santa Monica: Goodyear.

Hilb, M. (2005). New Corporate Governance: Successful Board Management Tools Berlin, Heidelberg, New York: Springer.

Illich, I. (2006) Exemption from school. Proportionality and the modern world. Moscow: Education.

Imai, M. (1986). Kaizen, the key to Japan's competitive success. New York: Random House Business

Krivtsova, S. V. \& Muhamatulina, E. A. (1997). Training: constructive interaction skills to adolescents. Moscow: Genesis.

Lvina, E. (2015). The Role of Cross-Cultural Communication Competence: Effective Transformational Leadership Across Cultures. Jurnal Ilmiah Peuradeun, 3(1), 1-18.

Mintzberg, H. (1983). Structure in fives: designing effective organizations. Englewood Cliffs, New York: Prentice-Hall.

Nonaka, I., Toyama, R. \& Hirata, T. (2008). Managing Flow: A Process Theory of the Knowledge-Based Firm. New York: Palgrave Macmillan.

Senge, P. M. (1990). The Fifth Discipline: The Art \& Practice of the Learning Organization. New York: Currency Doubleday. 
Sulaiman, S. (2015). Classroom Management and the Implications to Quality of Learning. Jurnal Ilmiah Peuradeun, 3(3), 431-440.

Whitmore, J. (1992). Coaching for Performance: Growing human potential and purpose. The principles and practice of coaching and leadership. London, Boston: Nicholas Brealey Publishing.

Yusoff, M. Z. M., \& Hamzah, A. (2015). Direction of Moral Education Teacher To Enrich Character Education. Jurnal Ilmiah Peuradeun, 3(1), 119-132.

ZA, T. (2014). Islamic Studies dalam Pendekatan Multidisipliner (Suatu Kajian Gradual Menuju Paradigma Global). Jurnal Ilmiah Peuradeun, 2(2), 211-234. 